of post-operative adjuvant therapy.Benefits of a laparoscopic approach are shorter hospitalisations, lower blood loss, faster postoperative recovery.

Methodology Safe, step by step method of total hysterectomy and bilateral salpingo-oophorectomy with pelvic and paraaortic lymph node dissection. Dissection and visualisation of anatomical landmarks as safest, most reliable method of performing laparoscopic surgery.

Result(s)* 54 year old woman with endometrial cancer G2 FIGO IB was qualified for laparoscopic surgery. Total hysterectomy and bilateral salpingo-oophorectomy with pelvic and para-aortic lymph node was performed. Patient was discharged from hospital after 3 days in good condition, with no significant blood loss or other complications.Final histopathology result : TIBN0M0 , 68 lymph nodes from paraaortic and pelvic lyphadectomy.LVSI negative

Conclusion* We are convinced that our approach to laparoscopic total hysterectomy with lymphadenectomy is safe and repetitive. By dissection and visualisation key anatomical landmarks we can avoid complications such as bleeding, damage to the ureters, nerves and vessels.

\section{MINI-INVASIVE (MIS) VS. OPEN SURGERY (OSU): PROGNOSTIC IMPACT OF THE SURGICAL APPROACH FOR ENDOMETRIAL CANCER. A FRANCOGYN COLLABORATIVE GROUP SURVEY}

${ }^{1} \mathrm{PF}$ Dupre* ${ }^{2} \mathrm{C}$ Rebahi, ${ }^{3} \mathrm{~J}$ Ognard, ${ }^{4} \mathrm{~S}$ Bendifallah, ${ }^{5} \mathrm{C}$ Akladios, ${ }^{6} \mathrm{M}$ Ballester, ${ }^{7} \mathrm{PA}$ Bolze, ${ }^{8} \mathrm{~N}$ Bourdel, ${ }^{9} \mathrm{G}$ Canlorbe, ${ }^{10} \mathrm{X}$ Carcopino, ${ }^{11} \mathrm{P}$ Collinet, ${ }^{12} \mathrm{C}$ Coutant, ${ }^{13} \mathrm{C}$ Huchon, ${ }^{14} \mathrm{~T}$ Gauthier, ${ }^{15} \mathrm{M}$ Koskas, ${ }^{16} \mathrm{~L}$ Ouldamer, ${ }^{17} \mathrm{~F}$ Kridelka, ${ }^{4} \mathrm{C}$ Touboul, ${ }^{18} \mathrm{H}$ Azaïs, ${ }^{19} \mathrm{~V}$ Lavoue. ${ }^{1} \mathrm{CHRU}$ Brest, Breast and Gynaecological Oncology Unit, Brest, France; ${ }^{2} \mathrm{CHRU}$ Brest, Brest And Gynaecological Oncology Unit, Brest, France; ${ }^{3}$ University of West Brittany, LaTIM UMR 1101, Brest, France; ${ }^{4}$ Hôpital Tenon APHP, Breast and Gynaecological surgery, Paris, France; ${ }^{5} \mathrm{CHU}$ de Hautepierre Strasbourg, Chirurgie Gynécologique, Strasbourg, France; ${ }^{6}$ Hôpital des Diaconesses Croix Saint Simon, Chirurgie, Paris, France; ${ }^{7} \mathrm{HCL}$ Lyon Sud, Chirurgie Gynécologique, Pierre-Bénite, France; ${ }^{8} \mathrm{CHU}$ Clermont Ferrand, Chirurgie Gynécologique, Clermont Ferrand, France; ${ }^{9}$ Hôpital Pitié Salpétrière, Chirurgie Gynécologique et mammaire, Paris, France, ${ }^{10}$ APHM Hôpital nord, Chirurgie Gynécologique, Marseille, France; ${ }^{11}$ CHRU Lille Hôpital Jeanne de Flandres, Chirurgie Gynécologique, Lille, France; ${ }^{12}$ Centre GF Leclerc, Surgical Oncology, Dijon, France; ${ }^{13}$ APHP Hôpital Lariboisière, Chirurgie Gynécologique, Paris, France; ${ }^{14} \mathrm{CHRU}$ Limoges, Chirurgie Gynécologique, Limoges, France; ${ }^{15}$ APHP Hôpital Bichat, Chirurgie Gynécologique, Paris, France; ${ }^{16} \mathrm{CHRU}$ Tours Bretonneau, Chirurgie Gynécologique, Tours, France; ${ }^{17} \mathrm{CHU}$ Liège, Chirurgie Gynécologique, Liège, Belgium; ${ }^{18}$ Hôpital Georges Pompidou, Chirurgie Ontologique Gynécologique et Mammaire, Paris, France; ${ }^{19} \mathrm{CHRU}$ Rennes, Gynaecological Oncology, Rennes, France

\subsection{6/ijgc-2021-ESG0.134}

Introduction/Background* Thanks to technical improvements, total non-conservative hysterectomy evolved towards MIS as the standard approach for early-stage endometrial cancer (EC). MIS has recently been called into question for cervical cancer treatment due to its negative prognosis impact. In this context, we carry out a study comparing OSu vs. MIS with Disease Free Survival (DFS) as primary endpoint.

Methodology Retrospective study, within the French collaborative group FRANCOGYN from 1999 to 2020. All patients aged over 18 who achieved hysterectomy for endometrial cancer were included whatever the pathological subtype. Secondary endpoints were: Overall Survival (OS) and sub-group analysis according to FIGO stage, ESMO-ESGO-ESTRO Consensus Conference risk-group 2015 (E3CC), pathological sub- types, lymph node metastasis and lympho-vascular space invasion (LVSI). To assess primary endpoint, we use inverse probability of treatment weighting (IPW) based on propensity score to construct two weighted cohort.

A Cox proportional-hazard model standard multivariate analysis was used for subgroup analysis.

Result(s)* Nine hundred and forty-five (945) patients were included, 380 (40.2\%) received OS and 565 (59.8\%) received MIS. The median follow-up was 34.2 months (29.1 SD) . The study other measured characteristics were strongly unbalanced in disfavor of the OSu group for pathological subtype $(p<0.001)$, FIGO stage $(p<0.001)$ and ESMOESGO-ESTRO risk group $(\mathrm{p}<0.001)$. Hence, after propensity score matching, Cox proportional-hazards model displays a trend of worse DFS in the OSu group $(\mathrm{HR}=0.72,95 \% \mathrm{CI}$ $0.52-1.00 \mathrm{p}=0.054)$ and significantly altered $\mathrm{OS}$ in the OSu vs. MIS group $(\mathrm{HR}=0.52,95 \%$ CI $0.35-0.78 \mathrm{p}=$ 0.0018).

DFS was significantly impaired by the following characteristics: Age, BMI, histological grade 3 (HR=2.04, 95\% CI $[1.15-2.04] \mathrm{p}=0.015)$, E3CC High Risk Group $(\mathrm{HR}=$ 2.62, 95\% CI [1.03-6.67] $\mathrm{p}=0.43)$ and FIGO Stage 3 $(\mathrm{HR}=2.21,95 \%$ CI $[1.07-4.56] \mathrm{p}=0.031)$

Conclusion* This study cover 20 years of clinical practice and consolidate MIS place for EC surgical treatment with an increasing use of MIS over years whatever the FIGO staging and clinical characteristics.

Every effort should be made to improve a standardized MIS approach the more that patient is frail or at high risk of relapse.

\section{MOLECULAR CLASSIFICATION OF ENDOMETRIAL CARCINOMA SUBSTANTIALLY CHANGING RISK- ASSESSMENT: RESULTS FROM A EUROPEAN MULTICENTRE INITIATIVE}

${ }^{1} \mathrm{~S}$ Kommoss ${ }^{*},{ }^{1} \mathrm{M}$ Grube, ${ }^{2} \mathrm{~K}$ Knoll, ${ }^{3} \mathrm{~A}$ Lum, ${ }^{4} \mathrm{C}$ Brambs, ${ }^{5} \mathrm{~N}$ Pauly, ${ }^{6} \mathrm{~F}$ Kommoss, ${ }^{7} \mathrm{~S}$ Heublein, ${ }^{8} \mathrm{M}$ Battista, ${ }^{1} \mathrm{~S}$ Mittelstadt, ${ }^{1} \mathrm{~A}$ Rohner, ${ }^{1} \mathrm{~T}$ Preaetorius, ${ }^{9} \mathrm{~A}$ Hasenburg, ${ }^{5 ; 10} \mathrm{~B}$ Ataseven, ${ }^{11} \mathrm{~A}$ Talhouk, ${ }^{12} \mathrm{~J}$ Diebold, ${ }^{2} \mathrm{AG}$ Zeimet, ${ }^{13} \mathrm{~A}$ Staebler, ${ }^{11} \mathrm{~J}$ Mcalpine. ${ }^{1}$ Tübingen University Hospital, Department of Women's Health, Germany; ${ }^{2}$ Innsbruck Medical University, Department Gynecology and Obstetrics, Austria; ${ }^{3} B C$ Cancer Research Centre, Molecular Oncology, Vancouver, Canada; ${ }^{4}$ Lucerne Cantonal Hospital, Department Gynecology and Obstetrics, Lucerne, Switzerland; ${ }^{5}$ Kliniken Essen Mitte (KEM), Department of Gynecology and Gynecologic Oncology, Germany; ${ }^{6}$ Heidelberg University Hospital, Institute of Pathology, Germany; ${ }^{7}$ Heidelberg University Hospital, Department Gynecology and Obstetrics, Heidelberg, Germany; ${ }^{8}$ University Medical Centre of the Johannes Gutenberg University Mainz, Department of Gynaecology and Obstetrics; ${ }^{9}$, Mainz University Hospital, Department Gynecology and Obstetrics; ${ }^{10}$ Frauenklinik in der Maistraße, München, Germany; ${ }^{11}$ University of British Columbia and British Columbia Cancer Agency, Division of Gynecologic Oncology, Canada; ${ }^{12}$ Lucerne Cantonal Hospital, Institute of Pathology, Lucerne, Switzerland; ${ }^{13}$ Tübingen University Hospital, Institute of Pathology and Neuropathology, Germany

\subsection{6/ijgc-2021-ESG0.135}

Introduction/Background* Endometrial carcinoma patient care was based on histopathologic examination for many years. However, conventional pathologic features are known to suffer from high inter-observer variability and may be irreproducible in many cases. TCGA-derived molecular classification was shown to provide clinically meaningful data and was recently introduced to ESGO/ESTRO/ESP endometrial carcinoma consensus guidelines. It was the aim of this study to quantify 